\title{
The temperature distribution during the microwave drying of wooden elements for structural defects in buildings
}

\author{
Jindřich Sobotka ${ }^{1, *}$, and Radim Smolka ${ }^{1}$ \\ ${ }^{1}$ Brno University of Technology, Faculty of Civil Engineering, Institute of Building Structures, \\ Veveří 95, 60200 Brno, Czech Republic
}

\begin{abstract}
This paper deals with the theory and application of microwave radiation and experimental optimization of microwave radiation for the distribution of temperature field in the irradiated wooden elements. The article describes the experimental work performed at the Faculty of Civil Engineering, in close cooperation with the company S. P. UNI, s.r.o.. Analysis of the research results was to determine the optimal intensity of microwave emitters and the necessary length of exposure to moist building materials microwave radiation with respect to a particular type of a wooden element. A part of the research was divided into several separate experiments. In each experiment the heating under various conditions was carried out on: I.- samples of the same size, but different weight moisture content, irradiated in the same time periods, II.- samples of the same size, same weight moisture content, irradiated for different time periods.
\end{abstract}

\section{Introduction}

Microwave is known as a part of electromagnetic radiation with a frequency from $300 \mathrm{MHz}$ to $300 \mathrm{GHz}$, corresponding to wavelengths from $1 \mathrm{~m}$ to $1 \mathrm{~mm}$. For industrial purposes it is globally determined by the frequency of $2.45 \mathrm{GHz}$, corresponding to a wavelength of 12.2 $\mathrm{cm}$. Such wavelength is also used in our applications [1].

Microwave Technology (EMW technology) is used in construction mainly for drying of damp structures, or as a way of disposal of biotic pests. In most cases, when heating the material, only the surface temperature of the front side is controlled. Temperatures reached at a depth are only estimated. And it is actually a heating depth and a distribution of temperature field that has a major impact on the speed and quality of the performed remediation. Without sufficient knowledge about how the material is heated, there is a risk of damage of the drying material.

Microwaves belong to the broad spectrum of electromagnetic waves, which also include a visible light region which is governed by Maxwell's equations.

It is applied, that the vectors characterizing the magnetic and electric fields are in every point and in every moment perpendicular to each other and both are perpendicular to the direction of wave motion (Fig. 1).

\footnotetext{
*Corresponding author: sobotka.j@,fce.vutbr.cz
} 
Their amplitudes have a constant ratio and in a vacuum, the electromagnetic waves move with a speed of light and so the following relation is applied:

$$
\lambda=\frac{c_{\lambda}}{f}
$$

where: $\quad \lambda \quad$ length of wave (m)

$\mathrm{c}_{\lambda} \quad$ velocity of wave propagation $\left(\mathrm{m} \cdot \mathrm{s}^{-1}\right)$

f frequency of microwave radiation $(\mathrm{Hz})-(2450 \mathrm{MHz})$. [1]

In assessing the possibility of using microwave technology in civil engineering practice it is necessary to realize the following aspects:

- the law of conservation of energy always applies;

- the microwave radiation penetrates some materials (glass, porcelain, ceramics, concrete, wood);

- certain material is by EMW radiation reflected (metals);

- by some materials the radiation is "absorbed" (water).

The changeover mechanism of the microwave energy to heat is given by:

$$
P=2 \cdot \pi \cdot f \cdot \varepsilon^{\prime} \cdot \varepsilon^{\prime \prime} \cdot E^{2}
$$

where: $\quad \mathrm{P}$ energy absorbed per unit volume $\left(\mathrm{W} \cdot \mathrm{m}^{-1}\right)$,

$\mathrm{f}$ frequency of microwave radiation $(\mathrm{Hz})-(2450 \mathrm{MHz})$,

$\varepsilon^{\prime} \quad$ permittivity $\left(\mathrm{F} \cdot \mathrm{m}^{-1}\right)$,

$\varepsilon^{\prime \prime} \quad$ dielectric loss factor of the material,

E intensity of the electric field inside the material $\left(\mathrm{V} \cdot \mathrm{m}^{-1}\right) .[1]$
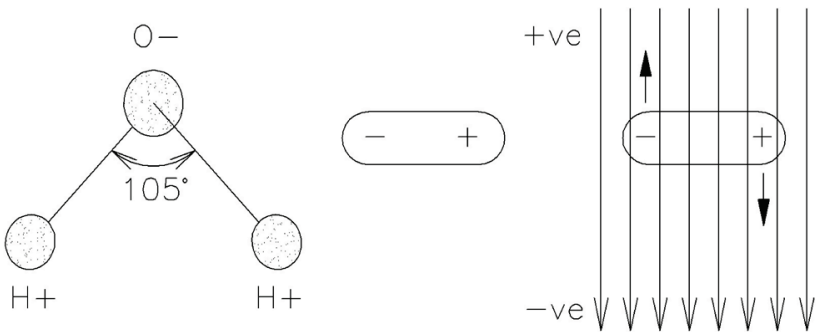

Fig. 1. Water molecule and its orientation in an electric field [5].

In the process, it is necessary to realize that water molecules tend to adjust their polarities changing the polarity of the electromagnetic microwave flux. This leads to the electromagnetic transformation of energy in kinetic energy. Fast movement of molecules and their mutual rubbing is subsequent kinetic energy converted into thermal energy.

Most electromagnetic energy is absorbed and converted to heat energy by the water molecules, which will first come into contact with. The greater the distance of water molecules from the front of the irradiated side is, the less is the flow of electromagnetic energy acting upon them and also its heating.

Following factors have a major impact on the depth of the microwaves penetration:

- water content and its distribution, [3]

- performance of the equipment used. [4] [5]

In the context of long-term research of the usage of microwave technology in the construction industry, which takes place at BUT, Department of Civil Engineering in Brno, we have focused, among other things, on the drying of wooden elements. The entire part 
was divided into several independent experiments. In each experiment, the heating under various conditions was performed on:

- samples of the same size, but different moisture content, heated in the same time periods;

- samples of the same size, the same moisture content, heated for various time periods;

- samples of the same size, the same moisture content, heated in the same time periods, but at different distances from the source of EMW radiation;

- samples of the different size, the same moisture content, heated in the same time periods;

- samples composed of several layers.

\section{Methods and Material}

The SM planed lumber that has been for about three years, placed loosely on the edge was used for the experiment. The individual prisms were numbered and two holes with diameter of $4 \mathrm{~mm}$ were drilled on the rear side, so that its bottom had been distanced from the front side $40 \mathrm{~mm}$ and $80 \mathrm{~mm}$.

Two beams were used for the experiment. [1] The samples No.1 - 4 were cut from the first beam, the samples No. $5-8$ were cut from the second beam. The first set of samples No.1 - 4 was stored loosely under a roof for four weeks, so that the samples absorbed only the moisture from the air.

The second set, samples No. 5 - 8, was artificially moistened. The samples were soaked in the water bath for 12 hours and subsequently sealed in PVC containers for 72 hours and taken out about 1 hour before the beginning of irradiation. Hereby was achieved a significant difference in moisture content between the samples No. 1 - 4 and No. 5 - 8 .

On average, there was an increase of humidity of $12 \%$ in the surface layer of $15 \mathrm{~mm}$. Weight moisture content was measured by digital stylus hygrometer "Greisinger GMR 110". For measurements at the greater depths the thermometer with a surface treatment of the probe "Greisinger GMH 1170" was used.

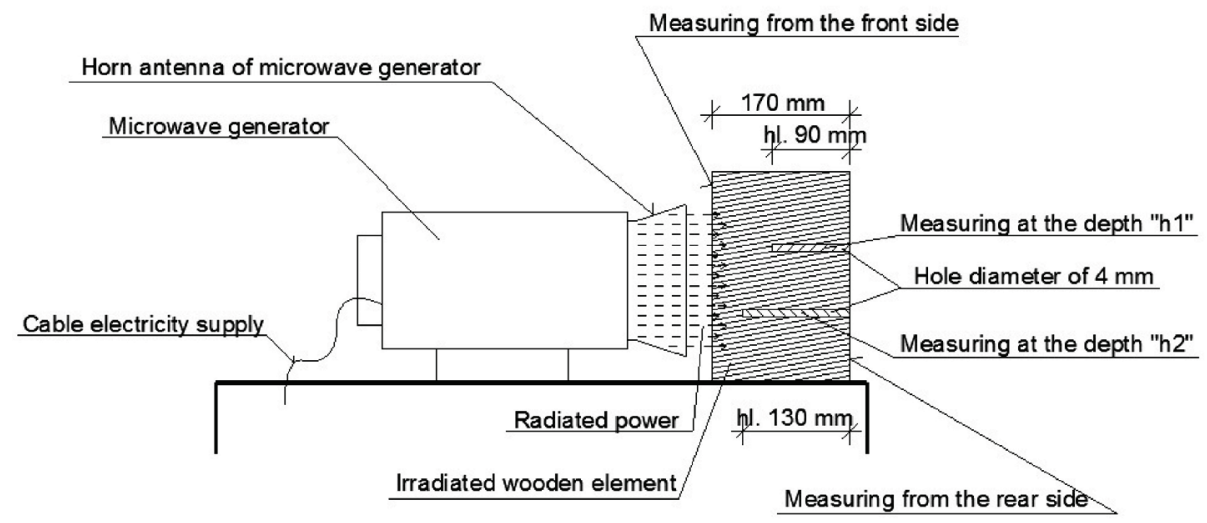

Fig. 2. View of the diagram of the wood element during irradiation.

The irradiation apparatus MB electronic were used, with a power of $1100 \mathrm{~W}$ and $750 \mathrm{~W}$ radiated power. The heating time was for all samples equal, 10 minutes.

Only one piece of wooden prism was irradiated. The prisms were erected vertically and with dimension of $170 \mathrm{~mm}$ in the direction of heat flow = wave (parallel to the antenna of the microwave generator).

Immediately after heating, the surface temperatures on the front and rear side were measured by thermal cameras. Subsequently, the temperature at the bottom of the drilled 
holes in different depths was determined by the depth thermometer with a special temperature sensor.

\section{Results}

In the first set of experiments, the samples with air humidity were heated. Measured values are shown in Table 1.

Table 1. Temperature values of wood samples measured in the first set.

\begin{tabular}{|c|c|c|c|c|c|c|}
\hline $\begin{array}{c}\text { Cross } \\
\text { section of } \\
\text { element } \\
{[\mathbf{m m}]}\end{array}$ & $\begin{array}{c}\text { Moisture } \\
\text { content } \\
{[\%]}\end{array}$ & $\begin{array}{c}\text { Time } \\
{[\mathbf{m i n}]}\end{array}$ & $\begin{array}{c}\text { Front } \\
\text { side }=\text { reverse } \\
{\left[{ }^{\circ} \mathbf{C}\right]}\end{array}$ & $\begin{array}{c}\text { Temperature at } \\
\text { the probe } \mathbf{9 0} \mathbf{~ m m} \\
{\left[{ }^{\circ} \mathbf{C}\right]}\end{array}$ & $\begin{array}{c}\text { Temperature at } \\
\text { the probe } \mathbf{1 3 0} \mathbf{~ m m} \\
{\left[{ }^{\circ} \mathbf{C}\right]}\end{array}$ & $\begin{array}{c}\text { Rear } \\
\text { side=obverse } \\
{\left[{ }^{\circ} \mathbf{C}\right]}\end{array}$ \\
\hline $\begin{array}{c}140 \times 170 \\
\text { n. } 1\end{array}$ & 13.5 & 10 & 98.6 & 79.0 & 68.2 & 39.8 \\
\hline $\begin{array}{c}140 \times 170 \\
\text { n. } 2\end{array}$ & 13.45 & 10 & 98.2 & 86.7 & 66.6 & 37.3 \\
\hline $\begin{array}{c}140 \times 170 \\
\text { n. } 3\end{array}$ & 13.5 & 10 & 91.8 & 80.6 & 63.1 & 36.2 \\
\hline $\begin{array}{c}140 \times 170 \\
\text { n. } 4\end{array}$ & 13.55 & 10 & 93.0 & 71.3 & 65.3 & 34,1 \\
\hline
\end{tabular}
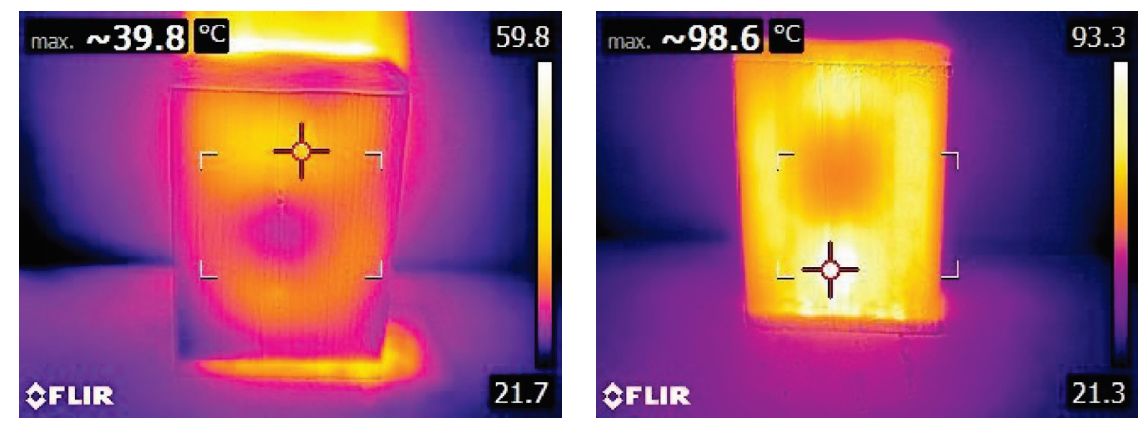

Fig. 3. Example of thermography images of the measured wooden samples of the first set.

\section{Surface and internal temperatures of the first set of wooden elements}
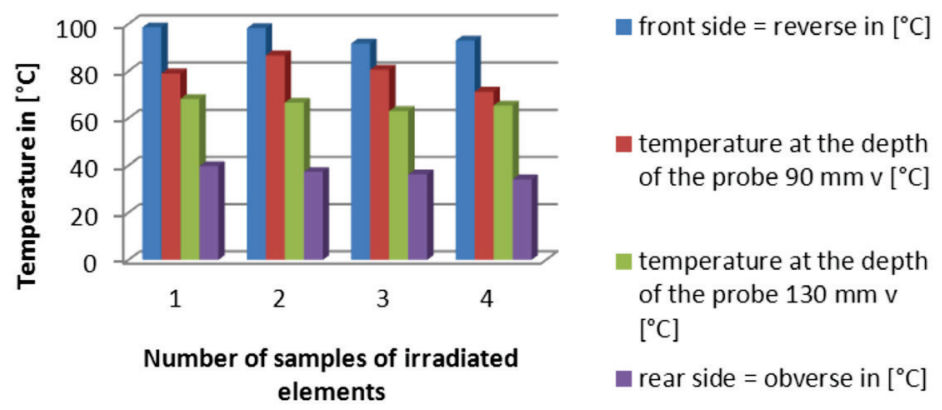

Fig. 4. Measured and evaluated surface and internal temperatures in the first set of samples. 
In the second set of experiment the moisten samples were heated. Measured values are given in Table 2 .

Table 2. Temperature values of wood samples measured in the second set.

\begin{tabular}{|c|c|c|c|c|c|c|}
\hline $\begin{array}{c}\text { Cross } \\
\text { section of } \\
\text { element } \\
{[\mathbf{m m}]}\end{array}$ & $\begin{array}{c}\text { Moisture } \\
\text { content }[\%]\end{array}$ & $\begin{array}{c}\text { Time } \\
{[\mathbf{m i n}]}\end{array}$ & $\begin{array}{c}\text { Front } \\
\text { side=reverse } \\
{\left[{ }^{\circ} \mathbf{C}\right]}\end{array}$ & $\begin{array}{c}\text { Temperature at } \\
\text { the probe 90 } \mathbf{~ m m} \\
{\left[{ }^{\circ} \mathbf{C}\right]}\end{array}$ & $\begin{array}{c}\text { Temperature at } \\
\text { the probe 130 } \mathbf{~ m m} \\
{\left[{ }^{\circ} \mathbf{C}\right]}\end{array}$ & $\begin{array}{c}\text { Rear } \\
\text { side=obverse } \\
{\left[{ }^{\circ} \mathbf{C}\right]}\end{array}$ \\
\hline $\begin{array}{c}140 \times 170 \\
\text { n.5 }\end{array}$ & 24.5 & 10 & 79.3 & 67.1 & 54.1 & 30.9 \\
\hline $\begin{array}{c}140 \times 170 \\
\text { n.6 }\end{array}$ & 26.1 & 10 & 75.1 & 63.2 & 49.4 & 29.6 \\
\hline $\begin{array}{c}140 \times 170 \\
\text { n. } 7\end{array}$ & 24.6 & 10 & 85.3 & 61.7 & 45.7 & 31.2 \\
\hline $\begin{array}{c}140 \times 170 \\
\text { n. } 8\end{array}$ & 25.5 & 10 & 80.1 & 73.4 & 54.2 & 32.4 \\
\hline
\end{tabular}

Differences in the temperatures measured for the individual samples in the first and second sets of measurements have various causes, such as:

- resin,

- knots,

- size and direction of dried cracks etc.

Therefore, the average values from individual results of samples No. 1 - 4 and No. 5 - 8 were calculated and are shown in Table 3.

Table 3. Average temperature values in both sets.

\begin{tabular}{|l|c|c|c|c|c|}
\hline & $\begin{array}{c}\text { Moisture } \\
\text { content } \\
{[\mathbf{\%}]}\end{array}$ & $\begin{array}{c}\text { Front } \\
\text { side=reverse } \\
{\left[{ }^{\circ} \mathbf{C}\right]}\end{array}$ & $\begin{array}{c}\text { Temperature at } \\
\text { the probe } \mathbf{9 0} \mathbf{~ m m} \\
{\left[{ }^{\circ} \mathbf{C}\right]}\end{array}$ & $\begin{array}{c}\text { Temperature at } \\
\text { the probe 130 } \mathbf{~ m m} \\
{\left[{ }^{\circ} \mathbf{C}\right]}\end{array}$ & $\begin{array}{c}\text { Rear } \\
\text { side=obverse } \\
{\left[{ }^{\circ} \mathbf{C}\right]}\end{array}$ \\
\hline $\begin{array}{l}\text { Samples } \\
\text { No. 1 - 4 }\end{array}$ & $13.5 \%$ & 95.4 & 76.9 & 65.8 & 36.8 \\
\hline $\begin{array}{l}\text { Samples } \\
\text { No. 5-8 }\end{array}$ & $25.175 \%$ & 79.95 & 66.35 & 50.85 & 31.015 \\
\hline
\end{tabular}

\section{Evaluation}

All the measurements clearly showed that even in a relatively short time of irradiation, the irradiated areas were heated, but not only at the front side but also in a significant depth of the test prisms.

Primarily the water contained in the wood (surface, bound and free) is heated. [5] Increased surface temperature increases the intensity of evaporation. The temperature increase inside the material, due to the volume expansion generated pressure forces that push water in all directions, including to the surface of the irradiated element. However, there it is necessary to take into account all the factors that influence the transport of moisture in the wood. The effort to accelerate the process of drying moist wood of structural elements could be tempted to try to extend the period of intense heat radiation. In such cases, there is a risk of irreversible damage of the material, such as a shape changes, the emergence of other dried cracks or undesirable chemical changes in composition of wood. 
Differences in temperatures measured in the first and second part of the experiment have the following causes:

- for heating of large quantities of water contained in the wet samples, more energy is needed. Lower temperatures are achieved with the same amount of energy. [3]

- greater amount of water in the surface layers of the samples No. 5 - 8 absorbs the greater part of the microwave energy, so that the less energy penetrates to a depth. With the increase of temperature on the front side, the amount of evaporated water is increased, which in turn causes the cooling of the surface. The wetter the surface is, the greater the cooling is. [4]

Differences in the obtained temperatures are shown in Table 3.

\section{Conclusion}

The results of the experiments clearly showed that EMW is a progressive method of heating of the wood, not only on the surface but also in the depth. [1] [2] Appropriately selected procedure of alternating heating and cooling (stale humidity) allows to aim the optimal heating temperatures and thus to accelerate the drying process.

Under certain conditions, this technology can also be used in the disposal of biotic pests, especially wood-boring insects. Temperatures measured within the test elements highly exceeded the temperatures required to inactivate all of its forms of development. Utilization of EMW technology is subject to extensive knowledge in the area of thermal activity and moisture movement in various building materials.

This paper has been worked out under the project No. LO1408 "AdMaS UP - Advanced Materials, Structures and Technologies", supported by Ministry of Education, Youth and Sports under the „National Sustainability Programme I".

\section{References}

1. M. Novotny, K. Suhajda, J. Sobotka, J. Gintar, E. Suhajdova, Wood Res. 59, 389-400, (2014)

2. J. Sobotka, R. Smolka, MATEC Web Conf. 93, 01008 (2017)

3. T. Petricek, P. Kacalek, R. Smolka, AMR 1041, 71-74 (2014)

4. J. Sobotka, R. Kolar, AMM 861, 295-302 (2017)

5. D. Beckovsky, L. Vackova, T. Beckovska, J. Sobotka, J. Pencik, M. Lavicky, Wood Res. 61(4), 627-636 (2016) 